\title{
Making sense of an airline's logo makeover: The case of garuda Indonesia
}

\author{
A. Andana \& H. Mahardika \\ Department of Management, Faculty of Economics and Business, Universitas Indonesia, \\ Depok, Indonesia
}

\begin{abstract}
This study aims to explain the relationship between a logo makeover and its company's performance in the airline industry. Through the semiotic method, the authors propose that a logo makeover plays an important role in determining the ability of an airline to improve its service performance. Garuda Indonesia Airline has been selected as the sole case for the study. The company made significant changes to the shape, colour schemes, and typography of its logo in 2009. The Garuda's logo makeover was analysed using the Peirce's semiotic approach. The results indicate that a logo makeover has a positive influence, as much as $19.6 \%$ on the customer's brand attitude and $16.5 \%$ on the customer's brand commitment, while the rest is determined by other factors that are not included in the scope of this research, such as service quality and marketing strategy.
\end{abstract}

\section{INTRODUCTION}

Today, the airline industry has become more important and continues to be one of the fastestgrowing service industries. The implications have been profound for the airlines, for competition intensifies and consumers expect a higher quality of services. This led to a significant shift in the industry, where safety and operational excellence are no longer the most important factors to win the competition.

As many airlines have changed their course into one that is more service-oriented, several paths have been taken in a number of different cases. Garuda Indonesia is one airline company that offers a unique perspective in this regard. The company emerged as a five-star airline and held the best cabin crew award, in a matter of three years after commencing its Quantum Leap programme in 2009 (Zerlina et al., 2016). Part of Garuda's Quantum Leap strategy is its logo makeover.

In the airline industry, corporate identity plays a crucial role as a medium of communication to build corporate image in the eyes of the public and competitors (Seo \& Park, 2016). Prior research found that corporate identity is related to various issues, such as credibility and philosophy (e.g. Melewar, 2003). As experienced by Garuda Indonesia, to showcase its commitment to a better and new spirit of quality services, the company also needs the presence of an improved corporate image as an airline. As a flag carrier airline for Indonesia, the new image formulation has to reflect the sense of a distinctive Indonesia, professionalism, adherence to international standard, and premium service.

One way to find out the meaning of logo makeover is by using the study of semiotics. Pateda in Sobur (2013) contends that the Peirce semiotic approach can help to understand how a 'signal' creates a unique state of mind, and therefore a strong brand name or logo (which creates a strong 'signal') is needed to achieve a competitive advantage. Hence, the appropriate logo redesign can help increase brand awareness in consumers' minds. Keller (1998) found strong evidence that the clarity of logos creates certain meanings and associations which can shape consumers' perceptions of the company. Like brand names, logos can acquire associations through their inherent meaning as well as through the supporting marketing programme. 


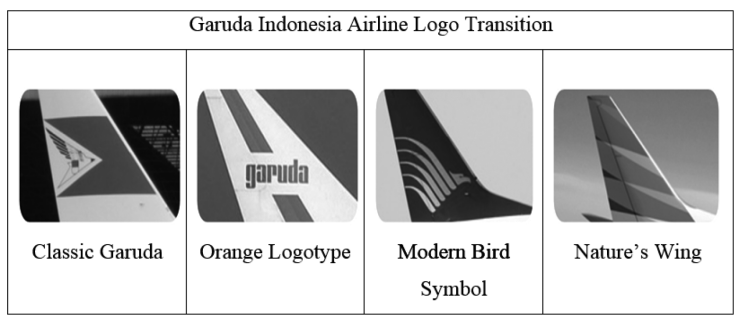

Figure 1. Garuda indonesia airline logo transition.

Zerlina et al. (2016) comments that the urgency of Garuda's management to present a more representative symbol in the form of a revised logo, is needed to signal the business restructuring that they were working on. The evolution of Garuda Indonesia's logo can be summarised as follows (see Figure 1).

As soon as the new logo was proposed in 2009, several big questions arose: 'Will the new logo play an important part in guiding Garuda on its road towards service excellence? If yes, can Garuda's path to excellence be replicated by other airlines?'

Answering these questions will be the main objective of this study. We would like to understand how the logo makeover affects service improvement in the airline industry. Logo redesign can be very expensive for some companies, and there is a high risk related to it. For example, a new logo sometimes has negative effects on the company's brand equity because the new design of the logo is too complex, unclear and hard to remember, unpleasant, or totally fails to create meanings for the consumers (Walsh et al., 2010).

\section{LITERATURE REVIEW}

Brand has always played a vital role as a corporate or product identity. It differentiates one from the rest and facilitates the introduction of the interaction between consumers and companies/products. On the brink of information overload, such as what is happening today, brand is a necessary cue for competition.

While undoubtedly important, there is no single effective approach to developing a good brand. According to Kotler et al. (2009), a brand name must be memorable, meaningful, likeable, transferable, adaptable, and protectable. The name, slogan, and logo of a product have also been used extensively to represent a brand. They function as a brief explanation or definition of what the brand is and what makes it special.

Among the different pillars of a brand, the logo plays a particularly key role in determining consumers' awareness towards the brand. Therefore, a logo must be special, recognisable, and unique. As difficult as it gets, many companies continuously change their logos in their search for perfection. However, changing the corporate logo is not a simple task to do. It is associated with resources, costs, and risks. The company will not only be burdened by the cost of changing the logo, but also by the risk of dispositioning the corporate image. A logo also contains the vision and missions of the company (most of the time, its founders) and also the value of the company.

As a widely-used terminology, 'logo' is often used to refer to a variety of graphs and typeface elements ranging from word-driven, conceptually simple logotypes and word marks, to image-driven, conceptually complex brand marks (Pittard et al., 2007). It is a vision of delivering a positive impression through a simple display in the form of a symbol. However, marketers encounter dilemmas as a logo should be able to convey its message over a prolonged period of time, and it must be able to adapt to cultural changes, while most logos do not. It might be exciting for the company to design a logo that is influenced by a trendy typeface, but before long it will become outdated and need to be replaced in later years. 
In responding to a brand, consumers convey their attitude by using brand elements that they have encountered. Attitude reflects a person's overall evaluation of a concept, and it is an inner feeling (affections, emotions, and moods) towards a product or a service offering (Mahardika et al., 2009). Consumers' attitude is always towards some concepts, including towards a certain brand. Recalling from the aforementioned discussion, brand attitude functions as the consumers' overall evaluation of various physical and social objects, including products, brands, models, stores, and people, as well as aspects of marketing strategy. Consumers can also have attitudes towards intangible objects, such as concepts and ideas.

In any circumstances, a brand must consistently stimulate a certain image in consumers' minds. Consistency is very important for a brand in today's competitive situation. Many companies have to deal with problems after making a very simple mistake, following a long period of excellent reputation. It is not easy for consumers to forgive mistakes, and they tend to punish any mistake as they rely on three factors in processing information regarding a brand, namely perception, emotions, and behaviour.

Consistency in the long run will create commitment. Commitment is the final phase in branding. Happy consumers will have a higher tendency to be committed to the brand, and therefore will prioritise it as their primary preference. In the case of the Garuda logo makeover, this brand commitment is the ultimate goal to achieve. However, it is also a risky venture since many companies fail in doing so. In order to induce a strong brand commitment, airlines should change their service delivery in accordance to the brand image. This is why understanding brand makeover is very important in the service industry.

\section{METHODOLOGY}

This research uses both qualitative and quantitative approaches. The qualitative approach was performed using a semiotic analysis on the logo, design, and other elements of the brand. It was also broadened into a more detailed semiotic analysis related to shape, colour, typography, branding, logo, design, and other graphic elements. In addition, we also discuss the role of each element of the logo related to the process of building brand attitude and brand commitment. The quantitative approach, on the other hand, was performed using a correlation analysis. We distributed questionnaires to respondents who had been frequent passengers (frequent flyer members of Garuda Indonesia Airline).

Overall, this research uses the mix of qualitative and quantitative approaches in order to complement each other. The result from exploration through the qualitative approach is explained further by a quantitative approach.

\subsection{Semiotic analysis}

As stated previously, the qualitative approach in this research mainly focuses on semiotics. According to Peirce and Welby (1977), three elements in semiotics are: icon, index, and symbol. Icon is the relationship between the sign and the object, or a reference in the form of two or three dimensions that are similar. Index is a sign that indicates natural relationships between signs and markers that are causal or have a causal relationship; it is a sign that directly refers to the fact. Symbol is a relationship that is arbitrary and based only on conventions. Symbols also include all languages in general (i.e. the language of a particular tribe or nation, alphabetical characters, punctuation, vocabulary, phrases, and sentences). As for numbers, the Morse code, traffic signs, and flag state need to be studied further to avoid mistakes. It is fundamentally a process of giving meaning to the signs consisting of three interconnected elements, namely: Representamen [R], Object [O] and Interpretant [I]. [R] is a sign that refers to something represented by [O], or the object as a reference, which is something referred to by the sign (denotatum). On the other hand, [I] is part of the process of interpreting the relationship between $[\mathrm{R}]$ and $[\mathrm{O}]$.

To measure the validity of this qualitative study, the process of interpretation of icon, index, and symbol, supported by the use of secondary data sources (literature from books, journals, and 


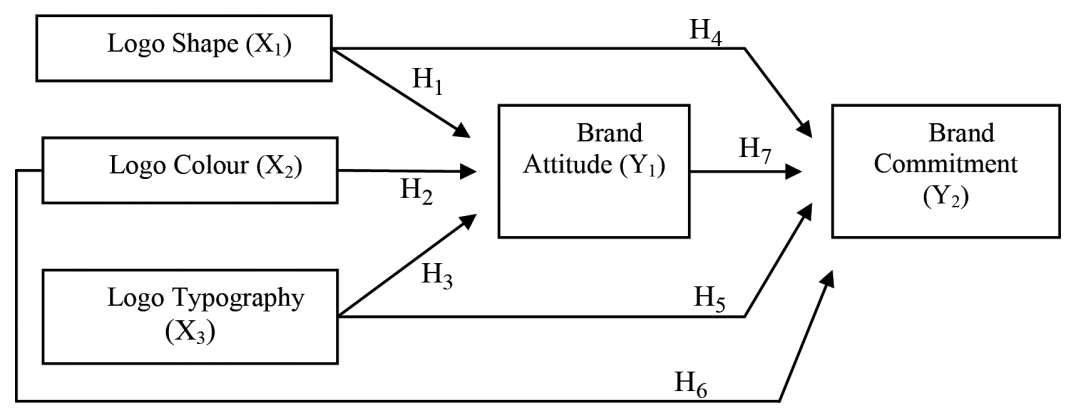

Figure 2. Research model.

online psychological articles) is also conducted. They have been obtained in order to engage with the meaning and message (verbal and non-verbal) contained in the new logo of Garuda Indonesia Airline through narrowing the logo elements into shape, colour, and typography. These main elements (shape, colour, and typography) were then put into the Peirce's semiotic instrument.

\subsection{Correlation analysis}

In order to strengthen the result of this study, we perform a follow-up examination by conducting a correlation analysis. It is aimed at examining the relationships between the logo makeover and the consumers' attitude. It is also aimed at providing an assessment of the new Garuda Indonesia Airline logo, as to whether consumers like or dislike it. We recruited 100 frequent flyer passengers of Garuda Indonesia Airline. The sampling technique chosen for this research is convenience sampling, using a non-random questionnaire distribution. We distributed the questionnaire both online and offline. The online questionnaire was made using the Google Docs service.

\subsection{Hypotheses}

Ultimately, this study aims at examining the influence of logo (shapes, colours, and typography) as a key brand element towards Garuda Indonesia's consumers' judgment (brand attitude and brand commitment), after the logo makeover. The conceptual framework can be seen as follows (see Figure 2).

In summary, based on the aforementioned discussion, we formulated each hypothesis as follows:

H1: Logo shape makeover is positively related to consumers' brand attitude.

H2: Logo colour makeover is positively related to consumers' brand attitude.

H3: Logo typography makeover is positively related to consumers' brand attitude.

H4: Logo shape makeover is positively related to consumers' brand commitment.

H5: Logo colour makeover is positively related to consumers' brand commitment.

H6: Logo typography makeover is positively related to consumers' brand commitment.

H7: Logo shape, logo colour, logo typography makeover is positively related to consumers' brand commitment with brand attitude as a mediating variable.

Descriptive and inferential statistics were analysed using SPSS.

\section{RESULTS}

\subsection{Semiotics analysis}

Based on the findings as a result of the survey of various literatures, it is revealed that most airline logos are associated with flying objects, which are dominated by symbols of a bird. 
This can be explained easily since the bird is an animal that has the ability to fly high in the sky. By employing the bird symbol, airline companies want their fleets to have a bird-like quality and agility (i.e. being capable of flying away around the world). A variety of birds have been traditionally selected by airline companies to be used as their logos, such as pigeon, eagle, and mythical birds like Garuda.

Several airlines also combine the bird symbol with other objects. Flag carriers (the national carriers) are commonly the ones with historic logos that are the most eye-catching. Most of the ornate ones have been refreshed for the modern era and hence most of their shapes are decorated with curved lines and pastel colours. For example, some of the Middle East airlines infuse Arabic calligraphy or typography into their logos, and it works to convey brand distinctiveness. Low-cost airlines, on the other hand, have been at the forefront in making their airline colourful. Colour has played a key role for them since they need to get as much attention as they can for the lowest possible cost. Low-cost airlines also use celestial objects, such as suns, globes, and stars, similarly to signify a sense of distance or remoteness in space/ air, and arguably with an added potential for global or world-wide reach.

Through a careful review of most airlines logos, we conclude that there are a significant number of airlines that use bird symbols in their logos. They mostly combine the bird illustration with other objects in order to show the national identity and airline classification, as well as to strengthen its existence. Usually, the most specific airline logo can be found on the tail fin of the aeroplanes.

In the case of Garuda Indonesia Airline, in the process of the logo makeover, they have added an element of graphical effects to the logo. If we look more carefully at the logo located on the tail fin of Garuda Indonesia's aeroplanes, it contains some graphical effects, such as brush stroke, diagonalising, streamlining, and gradation. These effects represent the aspects of motion and speed as the manifestation of energy passing through substance, such as when the wind blows a flag or when something is painted clearly with the stroke of a paintbrush. In addition, it also works through the association to the direct effect of velocity. Streamlining is related to the technological and physical reduction of friction for faster speed, just like the speed of a flying arrow. The final category is gradation, which is the gradual thinning of lines. That element of the logo is found on Garuda Indonesia's new logo, which is called the 'Nature's Wings' logo. It seems to work slightly differently through a geometric illusion. Specifically, it is called the kinetic effect. It represents the increasing level of abstraction in the representation of speed/velocity/motion. The spiky shapes (streamlining) in the 'Nature's Wings' logo of Garuda Indonesia Airline refer to stability. This shows that Garuda Indonesia Airline is a stable airline company that stands unwavering through any threats. The 'spiky' shapes look like a solid triangle, implying a stable and dynamic condition (Munger, 2006).

With regard to this new logo, it can be inferred that the streamlining style combines aesthetics and technology. In addition, it has a high symbolic value, and this made Garuda Indonesia Airline decide to use this style on its tail fin logo. It is expected to show the public that Garuda Indonesia is a reputable, sophisticated, fast, and professional airline. It is expected to enhance the product contact, so that it can attract many passengers and give a positive contribution to the 'Quantum Leap' programme of the airline.

In the semiotic analysis, colours also have an important role. Colours have psychological meanings that can be delivered to the viewer. These meanings can support the branding for the airlines. Each airline company has its own consideration in implementing certain colours on its tail fin. The colours on Garuda Indonesia's tail fin are blue, turquoise, white, tosca green and grey. Blue is a colour associated with business because it evokes a sense of balance as well as calm intelligence. Turquoise and tosca green are basically the same but different in the colour element. These two colours are associated with finance, safety, and nature. They also represent harmony, freshness, ambition, and greed. White reflects innocence, purity, and cleanliness. Meanwhile, grey is closely related with authority, maturity, security, and stability.

To summarise, Garuda Indonesia Airline changes its logo by incorporating some elements. Those elements have philosophical messages whose purpose is to strengthen the logo in order to express corporate identity to potential passengers. 


\subsection{Results from the correlation analysis}

Overall, the results of the analysis and discussion of the study have shown that all hypotheses have been proven. The following are important points that need to be highlighted:

1. The Garuda logo makeover has a positive influence, with as much as $19.6 \%$ on the consumers' brand attitude. Each element of the Garuda logo is positively related to the consumers' brand attitude, and typography is the most crucial element.

2. The Garuda logo makeover has a positive influence, with as much as $16.5 \%$ on the consumers' brand commitment. Each element of the Garuda logo is positively related to the consumers' brand commitment, and colour is the most crucial element.

3. Considering the consumers' brand attitude and commitment, $19.6 \%$ and $16.5 \%$ of determination is considered a small portion of contribution (the maximum is of course $100 \%$ ), but even though it is only a small portion, the Garuda logo makeover has proven to be aligned with service improvement and the company's profitability.

4. Other factors, such as safety, ground handling, service level of front desk, air customer service, punctuality and having a pleasant flight, are also important for respondents. These factors also induce a positive influence towards the consumers' brand attitude and brand commitment.

5. Brand attitude is partially mediated by the relationship between the Garuda logo makeover and brand commitment.

\section{CONCLUSION}

The current Garuda Indonesia Airline logo makeover has a distinctive design in shape, colour, and typography. These changes can be analysed using the Peirce's semiotic approach.

The old Garuda bird symbol is still used, but the colour composition has changed. The new logo, which is called the 'Nature's Wings', has a spiky shape. From the design perspective, it is known as the kinetic effect. From the semiotic perspective, the spiky shape represents the increasing level of abstraction of speed/velocity/motion. By this semiotic perspective, as a proud flag carrier of Indonesia, Garuda Indonesia Airline intends to offer a fast airline service to bring passengers to their destinations.

The colours on the Nature's Wings logo are blue, turquoise, tosca green, white, and grey. From the semiotic and psychological perspectives, blue means professionalism, tosca green means freshness, white means cleanliness, grey means reputability and integrity. These colours deliver the message that Garuda Indonesia Airline is the proud flag carrier of Indonesia; it offers prime service quality and always brings the Indonesian atmosphere in its flight. The ground handling and aircraft cabin crew provide a warm and friendly service to the passengers. Through the colours, Garuda Indonesia Airline emphasises itself as a leading airline in Indonesia and always presents the Indonesian spirit in its service.

The results of the research on the Garuda logo makeover in relation to the brand attitude and brand commitment indicate several points as follows:

1. The Garuda logo makeover overall and partially has a positive influence, as much as $19.6 \%$ on the consumers' brand attitude. The rest is determined by other factors that are not included in the scope of this research. Based on the magnitude of the $t$ value, the typography element of the Garuda logo is the most crucial factor that affects the customers' brand attitude.

2. The Garuda logo makeover overall and partially has a positive influence, as much as $16.5 \%$ on the consumers' brand commitment. The rest is determined by other factors that are not included in the scope of this research. Based on the magnitude of the $t$ value, the colour element of the Garuda logo is the most crucial factor that affects the customers' brand commitment.

3. Brand attitude is partially mediated by the relationship between the Garuda logo makeover and brand commitment. 
4. From those findings, even though the portions $(19.6 \%$ and $16.5 \%)$ are considered small, the Garuda logo makeover has a positive influence on the consumers' brand attitude and brand commitment.

Overall, the results from this study provide insight into the role of the Peirce's semiotic approach in the logo design. It has validated the relationship between the logo makeover and the consumers' brand attitude and commitment. Future research needs to be undertaken in general with regards to the effect of the logo makeover on the overall image of a company, on both quantitative and qualitative levels.

There are several limitations inherent in this study. The limited object of the study and sample size may restrict generalisation of the study findings. The sampling technique adapted in the study may also limit the generalisation of the study findings. There are also other factors that are not included in the scope of this research, such as service quality, marketing strategy, safety, competition from other airlines, and organisation culture; however, those factors, in fact, have a bigger influence on determining the brand image.

\section{REFERENCES}

Baron, R. M., \& Kenny, D. A. (1986). The moderator-mediator variable distinction in social the moderator-mediator variable distinction in social psychological research: Conceptual, strategic, and statistical considerations. Journal of Personality and Social Psychology, 51(6): 1173-1182. doi:10.1037/0022-3514.51.6.1173.

Carlson, N. R., and Buskist, W. (1997). Psychology: the science of behavior. Allyn and Bacon.

Gujarati, D. (2003). Basic Econometrics. Sixth Edition. Jakarta: Erlangga.

Hasan, A. (2013). Marketing dan Case Study. Yogyakarta: Center for Academic Publishing Service (CAPS).

Kotler, P., Keller, K. L., Brady, M., Goodman, M. \& Hansen, T. (2009). Marketing Management. Essex, UK: Pearson Education Limited.

Mahardika, H., Ewing, M. \& Thomas, D. (2009). Comparing the temporal stability of behavioral intention, behavioral expectation and implementation intention. In Proceedings of the 2009 Australian and New Zealand Marketing Academy Conference, Melbourne, Australia.

Malhotra, N. K. (2010). Marketing research: An applied orientation. New Jersey: Pearson.

Melewar, T. C. (2003). Determinants of the corporate identity construct: a review of the literature. Journal of Marketing Communications, 9(4), 195-220. doi:10.1080/1352726032000119161.

Munger, D. (2006). The Emotion of Shapes. ScienceBlogs, 27 March. http://scienceblogs.com/ cognitivedaily/2006/03/27/the-emotion-of-shapes/\#comments.

Peirce, C. S., \& Welby, V. (1977). Semiotic and Significs the Correspondence between Charles S. Peirce and Lady Victoria Welby. Indiana University Press.

Peter, J. P. \& Olson, J. C. (2010). Consumer behavior \& marketing strategy. New York: McGraw Hill.

Pittard, N., Ewing, M. Jevons, C. (2007). Aesthetic theory and logo design: examining consumer response to proportion across cultures. International Marketing Review, 24(4), 457-473. doi:10.1108/02651330710761026.

Seo, E. J. \& Park, J. W. (2016). A study on the impact of airline corporate reputation on brand loyalty. International Business Research, 10(1), 59. http://dx.doi.org/10.5539/ibr.v10n1p59.

Sobur, A. (2013). Semiotics for Communication Bandung: Remaja Rosdakarya.

Supranto, J. \& Limakrisna, N. (2012). Guidance for Research. Jakarta: Mitra Wacana Media.

Turlow, C. \& Aiello, G. (2007). National pride, global capital: A social semiotic analysis of transnational visual branding in the airline industry. Visual Communication, 6(3), 305-344. https://doi. org/10.1177/1470357207081002.

Walsh, M. F. (2005). Consumer response to logo shape redesign: The influence of brand commitment. Order No. 3206844, University of Pittsburgh. https://search.proquest.com/docview/305449396?accountid=17242.

Walsh, M. F., Winterich, K. P. \& Mittal, V. (2010). Do logo redesigns help or hurt your brand? The role of brand commitment. Journal of Product \& Brand Management, 19(2), 76-84. doi:10.1108/10610421011033421.

Widagdo. (2000). Design and Culture. Bandung: Dirjen Dikti Depdiknas.

Zerlina, A., Haryono, E. \& Elvianti, W. (2016). Optimizing the implementation of quantum leap program to face the challenges of ASEAN open sky policy: Lessons from Garuda Indonesia. Aegis: Journal of International Relations, 1(1). http://e-journal.president.ac.id/presunivojs/index.php/ AEGIS/article/view/75/588. 